\title{
THE ASSOCIATION BETWEEN FRUIT AND VEGETABLE CONSUMPTION AND MENTAL HEALTH DISORDERS: EVIDENCE FROM FIVE WAVES OF A NATIONAL SURVEY OF CANADIANS
}

Seanna E. McMartin, $\mathrm{MSc}^{1}$

Felice N. Jacka, $\mathrm{PhD}^{2,3}$

Ian Colman, $\mathrm{PhD}^{1}$

\section{Affiliations:}

1. Department of Epidemiology and Community Medicine, University of Ottawa, Ottawa, Ontario.

2. Barwon Psychiatry Research Unit, Deakin University, Geelong, Australia

3. Department of Psychiatry, The University of Melbourne, Melbourne, Australia

Corresponding author information: Dr. Ian Colman, Department of Epidemiology and Community Medicine, University of Ottawa, 451 Smyth Road, Room 3230C, Ottawa, Ontario, K1H 8M5, Canada

email: icolman@uottawa.ca Phone: +1 6135625800 x8715 Fax: +1 6135625465

Word Count: abstract: 197 text: 2,567

Pages: 19

Table(s): 4

Figure(s): 1

Conflict of Interest: The authors declare that they have no conflicts of interest. 


\section{Fruit and Vegetable Consumption and Mental Health Disorders}

\section{ABSTRACT}

Objective: The objective of this study was to examine the association between fruit and vegetable intake (FVI) and mental health disorders.

Method: This study used data from the Canadian Community Health Survey (CCHS), a repeated cross-sectional study of Canadians with five waves between 2000 until 2009 ( $n=258,357$ aged 12 years or older). FVI was assessed based on frequency of consumption. The primary outcome was a major depressive episode over the previous 12 months. Logistic regression models adjusted for age, gender, household income, education, physical activity, chronic illness and smoking.

Results: In the first wave, greater FVI was significantly associated with lower odds of depression (OR:0.86; 95\% CI:0.80-0.92). A combined estimate of all 5 waves demonstrated similar results (OR:0.72; 95\% CI: 0.71-0.75). Relative to those with the lowest FVI, those with the greatest FVI also had significantly lower odds of suffering from distress (OR: $0.8595 \%$ CI:0.76-0.95). These results were consistent across other waves. Perceived poor mental health status and previous diagnosis of a mood disorder and anxiety disorder also demonstrated statistically significant inverse associations with FVI (all p<0.05).

Conclusion: These findings suggest a potentially important role of a healthy diet in the prevention of depression and anxiety.

Key Words: nutrition; diet; fruit and vegetable; mental health; depression; public health 


\section{INTRODUCTION}

Depression is a leading cause of disability around the world, affecting approximately $16 \%$ of people throughout their lifetime (Ustun et al., 2004). The economic costs of depression in the United States, directly through health care costs and indirectly through lost productivity due to disability, were estimated to be at least $\$ 77.6$ billion in 2000 (Greenberg et al., 2003).

Several studies have suggested that diet quality is inversely related to depression in adults (Akbaraly et al., 2009; Beydoun et al., 2010; Jacka et al., 2011b; Jacka et al., 2009; Jacka et al., 2010b; Kuczmarski et al., 2010; Munoz et al., 2009; Nanri et al., 2010; Sanchez-Villegas et al., 2009) and adolescents (Jacka et al., 2011a; Jacka et al., 2010a; McMartin et al., 2012; Oddy et al., 2009). Notably, dietary patterns rather than single nutrients have been identified as important predictors of depression (Akbaraly et al., 2009; Jacka et al., 2010b). The use of simple measures of diet quality is becoming widely accepted. A recent Canadian study compared diet quality index scores with other indicators of diet quality and found that simple indicators such as fruit and vegetable intake can measure diet quality well (Garriguet, 2009). Additional studies examining dietary patterns have demonstrated that fruit and vegetable intake is a primary component of a healthy dietary pattern (Jacka et al., 2011a; Jacka et al., 2010b; Nanri et al., 2010). In the present study, we examine the relationship between fruit and vegetable intake, as a marker of diet quality, and mental health using five waves of a national, population-based survey of Canadians. 


\section{Fruit and Vegetable Consumption and Mental Health Disorders}

\section{METHODS}

\section{Study Population}

This study used data from the Canadian Community Health Survey (CCHS). The CCHS is a large, repeated, cross-sectional national survey of Canadians aged 12 years and older with information related to health status, health care utilization, and heath determinants collected five times between 2000 and 2009 (Statistics Canada, 2011). Individuals were excluded from data collection if they were living on Indian Reserves or Crown Lands, living in prisons or health care facilities, full-time members of the Canadian Forces, or living in certain remote areas. A multistage sampling strategy was employed and approximately $98 \%$ of the target population was sampled. Details are available elsewhere (Statistics Canada, 2011).

The CCHS questionnaires include core content (including fruit and vegetable consumption) as well as optional modules that are chosen by individual provinces and territories (such as depression). In 2001 (wave 1), all Canadian provinces completed the depression module and were included in the analysis $(\mathrm{n}=125,428)$. In 2003 (wave 2), data from Newfoundland, Prince Edward Island (PEI), New Brunswick, Ontario, Alberta, and Yukon/Northwest Territories were completed and included in the analysis ( $\mathrm{n}=47,879)$. In 2005 (wave 3), PEI, Alberta, and British Columbia were included in the analysis (n=26,841). In 2007 (wave 4), Nova Scotia, New Brunswick, Quebec and Alberta completed the depression module and were included $(\mathrm{n}=$ 42,543). In 2009 (wave 5), PEI, Quebec, Saskatchewan, Alberta, and British Columbia were included in the analysis $(n=53,430)$.

Sample sizes for secondary outcomes also varied based on participation rates of individual provinces in the optional modules of the CCHS (see Tables 2 and 3 for details).

\section{Exposure of Interest: Fruit and Vegetable Intake}

The fruit and vegetable component of the CCHS asked participants how often they consumed fruits and vegetables each day based on the fruit and vegetable module in the Behavioural Risk Factor Surveillance System of the United States Centers for Disease Control and Prevention ((CDC), 2011).. The component included the following question: "Not counting juice, how often 


\section{Fruit and Vegetable Consumption and Mental Health Disorders}

do you usually eat fruit?" Subsequent questions included: "Not counting juice, how often do you usually eat fruit?”; "How often do you (usually) eat green salad?”; "How often do you (usually) eat carrots?"; "Not counting carrots, potatoes, or salad, how many servings of other vegetables do you usually eat?". Total fruit and vegetable intake was assessed by combining the responses to questions regarding consumption frequency of fruits (not counting juice), green salad, carrots and other vegetables (excluding potatoes). The score was divided into quartiles for analysis, with the lowest quartile (i.e., least consumption of fruit and vegetables) being the reference category. Fruit and vegetable intake was also assessed separately. Fruit juices are high in sugar and associated with weight gain and unhealthy dietary habits (Ludwig et al., 2001). Consequently, consumption of fruit juice was not included in the assessment of fruit and vegetable intake.

\section{Outcome of Interest: Mental Health}

The primary outcome of interest was whether or not the respondent experienced a major depressive episode over the previous 12 months, assessed using the Composite International Diagnostic Interview-Short form (CIDI-SF) (Kessler et al., 1998). The CIDI-SF is a 10-minute interview shown to have between $90 \%$ and $94 \%$ sensitivity in identifying a major depressive episode, as compared with the full CIDI (Kessler et al., 1998), an hour-long interview that identifies DSM-IV (American Psychiatric Association, 1994) depressive episodes. For each individual, the CIDI-SF produces a predictive probability of a major depressive episode in the past 12 months (Kessler et al., 1998). Individuals with a predictive probability of $90 \%$ or higher were considered as having major depression (a score of 5 or higher on a 0-8 scale) (Kessler et al., 1998). This corresponds to DSM-IV criteria for a major depressive episode - 5 of 9 depressive symptoms in a 2-week period during the past year, including either loss of interest or depressed mood (American Psychiatric Association, 1994).

Symptoms of psychological distress were also assessed. Distress was assessed using the Kessler Psychological Distress Scale (K6) (Kessler et al., 2002), a 6-item self-report measure of common symptoms of depression and anxiety over the previous 12 months, with scores ranging from 0 to 24. Participants with a score of 6 or higher were classified as having experienced distress over the previous 12 months (Schmitz et al., 2009). 


\section{Fruit and Vegetable Consumption and Mental Health Disorders}

Additional outcomes investigated were self-perceived mental health and physician-diagnosed mood and anxiety disorder as reported by the respondent. For the assessment of self-perceived mental health, responses were dichotomized for the purpose of this study ('poor/fair' versus 'good/very good/excellent'). Participants were also asked about chronic conditions diagnosed by a health professional. Participants were considered to have a mood disorder if they responded "yes" to the question "Do you have a mood disorder such as depression, bipolar disorder, mania or dysthymia?", and considered to have an anxiety disorder if they responded "yes" to the question "Do you have an anxiety disorder such as a phobia, obsessive-compulsive disorder or a panic disorder?"

\section{Covariates}

Analyses were adjusted for factors that could potentially confound the relationship between fruit and vegetable consumption and depression, as well as other mental health outcomes. These included: gender, age, total household income from all sources, highest level of education, physical activity level (active, moderate, inactive), smoking status (daily, occasional and never) and chronic illness (including diabetes, heart disease, cancer or hypertension). Body mass index (BMI) was considered a potential confounder, however, the association between FVI and depression was unchanged therefore BMI was not included in the analysis. Physical activity level was determined from a previously derived leisure physical activity index based on daily energy expenditure. This index categorizes individuals as 'active', 'moderately active' or 'inactive', based on a series of questions regarding the frequency and duration of various leisure activities (e.g., jogging, swimming, hockey) over the previous 3 months (Statistics Canada, 2006).

Three additional variables, collected in CCHS wave 1 only, were examined separately as potential confounders or effect modifiers factors in the relationship between fruit and vegetable consumption and depression: social support, self-esteem and mastery. Two forms of social support - emotional and informational — were assessed based with the Medical Outcomes Study (MOS) Support survey (Sherbourne and Stewart, 1991). The amount of social support in the form of emotional or informational support was determined based from the degree to which a series of questions about whether the participant reported has having someone to talk to, confide in or provide advice (Statistics Canada, 2001). A set of questions around positive feelings about 
oneself was used to assess individual self-esteem (Statistics Canada, 2001). Finally, mastery was assessed with a series of questions that measured the extent to which the participant felt in control of their life (Statistics Canada, 2001).

\section{Statistical Analyses}

The relationship between fruit and vegetable consumption and mental health was examined using logistic regression models. Regression results are reported as unadjusted and adjusted odds ratios (ORs). ORs were adjusted for gender, age, household income, education, physical activity level and smoking status. Additionally, ORs were adjusted for this first set of covariates, as well as social support, self-esteem, and mastery, respectively. Sampling weights were used to ensure the results were representative of the Canadian population. A meta-analysis of the five independent studies was performed to provide a crude overall estimate of the association between FVI and depression. The top three quartiles for total fruit and vegetable intake were combined to create a dichotomous variable for fruit and vegetable intake. Stata Statistical Software (Release 11) (Stata Corp., College Station, TX, USA) was used for these analyses. 


\section{Fruit and Vegetable Consumption and Mental Health Disorders}

\section{RESULTS}

Table 1 presents characteristics of the study population from wave 1. Of the 9,739 participants who reported depression in 2000-2001, 65\% were female (Table 1). Most participants with depression were in early (age 20-24) and late adulthood (age 35-50), achieved greater than a high school education (51.1\%), and earned middle to high income. Among participants with depression a higher proportion were physically inactive $(53.8 \%)$ and were smokers $(43.2 \%)$. These characteristics were consistent across other waves. The average frequency of FVI per day in wave 1 in $\mathrm{Q} 1=0.51, \mathrm{Q} 2=2, \mathrm{Q} 3=3$ and $\mathrm{Q} 4=5.4$.

Table 2 presents ORs (unadjusted and adjusted) for the association between fruit and vegetable consumption and depression. Greater fruit and vegetable consumption was significantly associated with lower odds of depression across most waves. In the first wave, relative to those who consumed the least amount of fruits and vegetables, the odds of depression were $15 \%$ lower among those who consumed the most. Similar results were seen in waves 2, 4 and 5. A pooled estimate for the effect of FVI on depression was calculated using information from all 5 cycles. Overall, greater fruit and vegetable consumption was associated with a $27 \%$ reduction in odds of depression relative to those consuming the least amount of fruits and vegetables (bottom $25^{\text {th }}$ percentile) (Figure 1).

Increased consumption of fruits and vegetables was associated with reduced odds of poor mental health across all secondary outcomes. Greater fruit and vegetable consumption was associated with lower odds of distress in waves $1,3,4$ and 5 (Table 2). In the first wave, relative to those who consumed the least amount of fruits and vegetables, those with the greatest consumption had $13 \%$ lower odds of suffering from distress. Poor perceived mental health, previous diagnosis of a mood disorder and anxiety disorder also demonstrated a statistically significant inverse association with fruit and vegetable consumption across waves 2 - 5 (Table 4).

The relationship between depression and fruit and vegetable consumption was also examined separately (Table 3). These results broadly show similar associations between both fruit and vegetable consumption and reduced likelihood of depression. Additional analyses were performed in cycle 1 examining whether the association changed or was modified according to 
social support, self-esteem and mastery. The association between fruit and vegetable consumption and depression was unchanged with the inclusion of these variables as covariates. In addition, there was no evidence of these variables modifying the relationship between fruit and vegetable consumption and depression (fruit \& vegetable/social support, fruit $\&$ vegetable/self-esteem, and fruit \& vegetable/mastery interaction terms all p>0.05). 


\section{Fruit and Vegetable Consumption and Mental Health Disorders}

\section{DISCUSSION}

In this large, population-based study of Canadians, greater fruit and vegetable consumption was associated with lower odds of depression, psychological distress, self-reported mood and anxiety disorders and poor perceived mental health.

These findings, observed across multiple cross-sectional samples from the Canadian population, are remarkably consistent and support previous studies showing that individuals with higher quality diets are less likely to suffer from depression or depressive symptoms (Jacka et al., 2010a; Jacka et al., 2011b; Jacka et al., 2010b; Kuczmarski et al., 2010; Munoz et al., 2009; Nanri et al., 2010; Oddy et al., 2009). These findings have significant implications for public health, given that, in 2004, half of adults were not meeting Canada's Food Guide recommendations of 5 fruits and vegetables per day (Garriguet, 2007).

It is notable that we found only inconsistent evidence of a dose-response relationship between fruit and vegetable intake and depression. Reduced odds of depression were, in two of the four waves, similar between those in the second, third and fourth quartiles. This suggests that meeting minimum requirements of fruit and vegetable consumption may be sufficient to provide beneficial effects on mental health. The results examining fruit and vegetable consumption separately are less consistent. These results provide little compelling evidence to suggest that one is more important than the other. This supports the idea that the contribution of consumption of fruits and vegetables towards better mental health may be due to a habitual dietary pattern associated with fruit and vegetable intake (Jacka et al., 2011a; Jacka et al., 2010b; Nanri et al., 2010) rather than actions of specific nutrients from fruits or vegetables (Akbaraly et al., 2009; Jacka et al., 2010b).

The underlying mechanism supporting the relationship between diet quality and mental health remains to be clarified. One study using animal models demonstrated that mice fed a high fat diet demonstrated signs of anxiety and depressive-like symptoms (Sharma and Fulton, 2012). A healthy diet comprised of a high intake of fruits and vegetables is rich in anti-oxidants, and consequently may dampen the detrimental effects of oxidative stress on mental health (Jacka and Berk, 2007; Joseph et al., 1998). Inflammation is also thought to contribute to the development 


\section{Fruit and Vegetable Consumption and Mental Health Disorders}

of depression. Studies have indicated that low magnesium intake and regular consumption of a diet with a high glycemic load is associated with higher plasma concentrations of C-reactive protein (CRP), a marker of low-grade inflammation (King et al., 2005; Liu et al., 2002). Green vegetables such as spinach are good sources of magnesium and folate, both of which appear play a role in depression.

There are several limitations to this study. The assessment of fruit and vegetable intake measured frequency of consumption, rather than quantity. Moreover, it did not include the consumption of vegetables from mixed dishes and consumption may therefore have been underestimated.

Finally, the cross-sectional design does not allow for causal inferences. Although depression was treated, conceptually, as an outcome variable, it may be that depression leads to the consumption of lower quality foods. However, recent prospective studies have not found evidence of reverse causality, reporting that baseline diet quality was associated with subsequent mental health, but baseline mental health was not associated with subsequent diet quality (Akbaraly et al., 2009; Jacka et al., 2011a; Sanchez-Villegas et al., 2009). Despite these potential limitations, however, this study also had several methodological strengths. It was a population-based study with a relatively high response rate and large sample size. Also, several important socio-demographic and psychological factors were controlled for in the analyses, allowing for a clearer interpretation of the main findings.

\section{CONCLUSIONS}

In conclusion, results from the present study suggest that fruit and vegetable intake, as part of an overall healthy diet, may play a role in depression and psychological distress. This has important public health implications due to the modifiable nature of diet, particularly given the low rate of adherence to national dietary guidelines by the majority of Canadians. Although the evidence linking diet and mental illness is very new, the consistency of the findings from numerous countries offers compelling support for diet quality as a potentially important factor in the prevention of mental illness. 


\section{ACKNOWLEDGEMENTS}

This research was undertaken, in part, thanks to funding from the Canada Research Chairs program for Dr. Colman. Assoc Prof Felice Jacka has received Grant/Research support from the Brain and Behavior Research Institute and the Australian National Health and Medical Research Council. She is supported by an Australian National Health and Medical Research Council Postdoctoral Training Fellowship (\#628912). The funders had no role in study design; collection, analysis and interpretation of data; the writing of the manuscript; or the decision to submit the manuscript for publication. 


\section{Fruit and Vegetable Consumption and Mental Health Disorders}

\section{REFERENCES}

Akbaraly, T.N., Brunner, E.J., Ferrie, J.E., Marmot, M.G., Kivimaki, M., Singh-Manoux, A., 2009. Dietary pattern and depressive symptoms in middle age. Brit J Psychiat 195:408-13.

American Psychiatric Association, 1994. Diagnostic and statistical manual of mental disorders (DSM-IV), 4th ed. American Psychiatric Association, Washington (DC).

Beydoun, M.A., Kuczmarski, M.T.F., Beydoun, H.A., Shroff, M.R., Mason, M.A., Evans, M.K., Zonderman, A.B., 2010. The Sex-Specific Role of Plasma Folate in Mediating the Association of Dietary Quality with Depressive Symptoms. J Nutr 140:338-47.

Centers for Disease Control and Prevention (CDC), 2011. Behavioural Risk Factor Surveillance System Questionnaire Atlanta, Georgia US Department of Health and Human Services, Centers for Disease Control and Prevention (CDC) Garriguet, D., 2007. Canadians' eating habits. Health Rep 18:17-32.

Garriguet, D., 2009. Diet quality in Canada. Health Reports 20.

Greenberg, P.E., Kessler, R.C., Birnbaum, H.G., Leong, S.A., Lowe, S.W., Berglund, P.A., Corey-Lisle, P.K., 2003. The economic burden of depression in the United States: How did it change between 1990 and 2000? J Clin Psychiat 64:1465-75.

Jacka, F., Berk, M., 2007. Food for thought. Acta Neuropsychiatr 19:321-23.

Jacka, F.N., Kremer, P.J., Berk, M., de Silva-Sanigorski, A.M., Moodie, M., Leslie, E.R., Pasco, J.A., Swinburn, B.A., 2011a. A Prospective Study of Diet Quality and Mental Health in Adolescents. Plos One 6.

Jacka, F.N., Kremer, P.J., Leslie, E.R., Berk, M., Patton, G.C., Toumbourou, J.W., Williams, J.W., 2010a. Associations between diet quality and depressed mood in adolescents: results from the Australian Healthy Neighbourhoods Study. Aust Nz J Psychiat 44:435-42.

Jacka, F.N., Mykletun, A., Berk, M., Bjelland, I., Tell, G.S., 2011b. The Association Between Habitual Diet Quality and the Common Mental Disorders in Community-Dwelling Adults: The Hordaland Health Study. Psychosom Med 73:483-90.

Jacka, F.N., Overland, S., Stewart, R., Tell, G.S., Bjelland, I., Mykletun, A., 2009. Association between magnesium intake and depression and anxiety in community-dwelling adults: the Hordaland Health Study. Aust Nz J Psychiat 43:45-52.

Jacka, F.N., Pasco, J.A., Mykletun, A., Williams, L.J., Hodge, A.M., O'Reilly, S.L., Nicholson, G.C., Kotowicz, M.A., Berk, M., 2010b. Association of Western and Traditional Diets With Depression and Anxiety in Women. Am J Psychiat 167:305-11.

Joseph, J.A., Shukitt-Hale, B., Denisova, N.A., Prior, R.L., Cao, G., Martin, A., Taglialatela, G., Bickford, P.C., 1998. Long-term dietary strawberry, spinach, or vitamin E supplementation retards the onset of age-related neuronal signal-transduction and cognitive behavioral deficits. J Neurosci 18:8047-55.

Kessler, R.C., Andrews, G., Colpe, L.J., Hiripi, E., Mroczek, D.K., Normand, S.L.T., Walters, E.E., Zaslavsky, A.M., 2002. Short screening scales to monitor population prevalences and trends in non-specific psychological distress. Psychol Med 32:959-76.

Kessler, R.C., Andrews, G., Mroczek, D.K., Ustun, T.B., Wittchen, H.-U., 1998. The World Health Organization Composite International Diagnostic Interview Short Form (CIDISF). Int J Methods Psychiatr Res:171-85.

King, D.E., Mainous, A.G., Geesey, M.E., Woolson, R.F., 2005. Dietary magnesium and C-reactive protein levels. J Am Coll Nutr 24:166-71. 


\section{Fruit and Vegetable Consumption and Mental Health Disorders}

Kuczmarski, M.F., Sees, A.C., Hotchkiss, L., Cotugna, N., Evans, M.K., Zonderman, A.B., 2010. Higher Healthy Eating Index-2005 Scores Associated with Reduced Symptoms of Depression in an Urban Population: Findings from the Healthy Aging in Neighborhoods of Diversity Across the Life Span (HANDLS) Study. J Am Diet Assoc 110:383-89.

Liu, S.M., Manson, J.E., Buring, J.E., Stampfer, M.J., Willett, W.C., Ridker, P.M., 2002. Relation between a diet with a high glycemic load and plasma concentrations of high-sensitivity C-reactive protein in middle-aged women. Am J Clin Nutr 75:492-98.

Ludwig, D.S., Peterson, K.E., Gortmaker, S.L., 2001. Relation between consumption of sugar-sweetened drinks and childhood obesity: a prospective, observational analysis. Lancet 357:505-08.

McMartin, S.E., Kuhle, S., Colman, I., Kirk, S.F., Veugelers, P.J., 2012. Diet quality and mental health in subsequent years among Canadian youth. Public Health Nutr 15:2253-58.

Munoz, M.A., Fito, M., Marrugat, J., Covas, M.I., Schroder, H., Investigators, R.H., 2009. Adherence to the Mediterranean diet is associated with better mental and physical health. Brit J Nutr 101:1821-27.

Nanri, A., Kimura, Y., Matsushita, Y., Ohta, M., Sato, M., Mishima, N., Sasaki, S., Mizoue, T., 2010. Dietary patterns and depressive symptoms among Japanese men and women. Eur J Clin Nutr 64:832-39.

Oddy, W.H., Robinson, M., Ambrosini, G.L., O'Sullivan, T.A., de Klerk, N.H., Beilin, L.J., Silburn, S.R., Zubrick, S.R., Stanley, F.J., 2009. The association between dietary patterns and mental health in early adolescence. Prev Med 49:39-44.

Sanchez-Villegas, A., Delgado-Rodriguez, M., Alonso, A., Schlatter, J., Lahortiga, F., Majem, L.S., Martinez-Gonzalez, M.A., 2009. Association of the Mediterranean Dietary Pattern With the Incidence of Depression The Seguimiento Universidad de Navarra/University of Navarra Follow-up (SUN) Cohort. Arch Gen Psychiat 66:1090-98.

Schmitz, N., Lesage, A., Wang, J.L., 2009. Should Psychological Distress Screening in the Community Account for Self-Perceived Health Status? Can J Psychiat 54:526-33.

Sharma, S., Fulton, S., 2012. Diet-induced obesity promotes depressive-like behaviour that is associated with neural adaptations in brain reward circuitry. International Journal of Obesity:1-8.

Sherbourne, C.D., Stewart, A.L., 1991. The Mos Social Support Survey. Soc Sci Med 32:705-14.

Statistics Canada, 2001. Canadian Community Health Survey (CCHS) Cycle 1.1 Derived Variables (DV) Specifications Ottawa Statistics Canada

Statistics Canada, 2006. Canadian Community Health Survey (CCHS) Cycle 3.1 (2005)

Public Use Micro Data File (PUMF) Integrated Derived Variable (DV) and Grouped Variable Specification Ottawa Statistics Canada

Statistics Canada, 2011. Canadian Community Health Survey - Annual Component (CCHS) Statistics Canada

Ustun, T.B., Ayuso-Mateos, J.L., Chatterji, S., Mathers, C., Murray, C.J.L., 2004. Global burden of depressive disorders in the year 2000. British Journal of Psychiatry 184:386-92. 


\section{Fruit and Vegetable Consumption and Mental Health Disorders}

Table 1. Sociodemographic and health characteristics of participants in wave 1 of CCHS (Canada, 2000).

\begin{tabular}{|c|c|c|}
\hline Characteristic & $\begin{array}{l}\text { Proportion of Study } \\
\text { Sample }(n=130,880)\end{array}$ & $\begin{array}{l}\text { Proportion of Depressed } \\
\text { Individuals }(n=9,739)\end{array}$ \\
\hline \multicolumn{3}{|l|}{ Age (years) } \\
\hline $12-14$ & 4.4 & 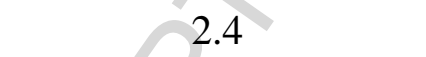 \\
\hline $15-19$ & 8.1 & 9.0 \\
\hline $20-24$ & 8.3 & 11.2 \\
\hline $25-29$ & 7.8 & 9.6 \\
\hline $30-34$ & 8.4 & 9.4 \\
\hline $35-39$ & 10.1 & 12.9 \\
\hline $40-44$ & 10.5 & 12.4 \\
\hline $45-49$ & 9.3 & 10.6 \\
\hline $50-54$ & 8.0 & 7.8 \\
\hline $55-59$ & 6.2 & 5.3 \\
\hline $60-64$ & 4.8 & 3.2 \\
\hline $65-69$ & 4.5 & 2.2 \\
\hline $70-74$ & 3.9 & 1.9 \\
\hline $75-79$ & 2.9 & 1.2 \\
\hline $80+$ & 2.9 & 1.2 \\
\hline \multicolumn{3}{|l|}{ Sex } \\
\hline Male & 2 & 35 \\
\hline Female & 50.7 & 65 \\
\hline \multicolumn{3}{|l|}{ Education } \\
\hline$<$ Secondary & 29.2 & 28.6 \\
\hline Secondary & 18.5 & 19.6 \\
\hline Other post secondar & 8.2 & 10.2 \\
\hline Post secondary & 43.2 & 40.9 \\
\hline \multicolumn{3}{|l|}{ Income } \\
\hline$<\$ 15,000$ & 7.7 & 13.2 \\
\hline$\$ 15,000-29,999$ & 14.3 & 17.3 \\
\hline$\$ 30,000-49,999$ & 20.2 & 20.8 \\
\hline$\$ 50,000-79,999$ & 24.5 & 23.0 \\
\hline$\$ 80,000+$ & 22.5 & 17.4 \\
\hline \multicolumn{3}{|l|}{ Physical Activity Level } \\
\hline Active & 21.0 & 20.8 \\
\hline Moderately Active & 21.6 & 20.4 \\
\hline Inactive & 49.1 & 53.8 \\
\hline \multicolumn{3}{|l|}{ Type of Smoker } \\
\hline Daily & 21.4 & 36.8 \\
\hline Occasional & 4.5 & 6.4 \\
\hline Not at all & 74.0 & 56.8 \\
\hline \multicolumn{3}{|l|}{ Chronic Illness } \\
\hline Absent & 81.6 & 81.3 \\
\hline Present & 18.3 & 18.6 \\
\hline
\end{tabular}




\section{Fruit and Vegetable Consumption and Mental Health Disorders}

Table 2. Odds ratios (OR) with $95 \%$ confidence intervals for the association between total fruit and vegetable intake and depression and distress (Canada, 2000-2009).

\begin{tabular}{|c|c|c|c|c|c|}
\hline \multicolumn{4}{|c|}{ Depression } & \multicolumn{2}{|c|}{ Distress } \\
\hline \multirow{3}{*}{$\begin{array}{l}\text { CCHS } \\
\text { Survey Cycle }\end{array}$} & & & CCHS & & \\
\hline & & & Survey Cy & & \\
\hline & $\begin{array}{l}\text { Crude OR } \\
(95 \% \text { CI }) \\
\end{array}$ & $\begin{array}{l}\text { Adjusted OR } \\
(95 \% \mathrm{CI})^{\mathrm{a}}\end{array}$ & & $\begin{array}{l}\text { Crude OR } \\
(95 \% \mathrm{CI})\end{array}$ & $\begin{array}{l}\text { Adjusted OR } \\
(95 \% \mathrm{CI})^{\mathrm{a}}\end{array}$ \\
\hline $2000-01$ & & & $2000-01^{b}$ & & \\
\hline Quartile 1 & 1.00 & 1.00 & Quartile 1 & 1.00 & 1.00 \\
\hline Quartile 2 & $0.75(0.69-0.82)$ & $0.83(0.76-0.91)$ & Quartile 2 & $0.91(0.81-1.03)$ & $1.02(0.90-1.16)$ \\
\hline Quartile 3 & $0.74(0.67-0.82)$ & $0.87(0.78-0.97)$ & Quartile 3 & $0.80(0.70-0.91)$ & $0.92(0.80-1.05)$ \\
\hline Quartile 4 & $0.76(0.71-0.82)$ & $0.85(0.78-0.92)$ & Quartile 4 & $0.75(0.68-0.83)$ & $0.87(0.78-0.98)$ \\
\hline 2003 & & & $2003^{c}$ & & \\
\hline Quartile 1 & 1.00 & 1.00 & Quartile 1 & 1.00 & 1.00 \\
\hline Quartile 2 & $0.67(0.57-0.81)$ & $0.79(0.67-0.95)$ & Quartile 2 & $0.73(0.58-0.90)$ & $0.85(0.66-1.09)$ \\
\hline Quartile 3 & $0.65(0.55-0.78)$ & $0.81(0.67-0.98)$ & Quartile 3 & $0.62(0.49-0.78)$ & $0.83(0.63-1.09)$ \\
\hline Quartile 4 & $0.69(0.59-0.82)$ & $0.83(0.69-1.01)$ & Quartile 4 & $0.56(0.44-0.71)$ & $0.84(0.63-1.13)$ \\
\hline 2005 & & & $2005^{d}$ & & \\
\hline Quartile 1 & 1.00 & 1.00 & Quartile 1 & 1.00 & 1.00 \\
\hline Quartile 2 & $0.85(0.68-1.04)$ & $0.94(0.75-1.19)$ & Quartile 2 & $0.67(0.58-0.77)$ & $0.70(0.60-0.82)$ \\
\hline Quartile 3 & $0.83(0.67-1.03)$ & $0.98(0.78-1.25)$ & Quartile 3 & $0.61(0.53-0.70)$ & $0.70(0.60-0.83)$ \\
\hline Quartile 4 & $0.84(0.69-1.04)$ & $0.95(0.75-1.22)$ & Quartile 4 & $0.67(0.58-0.78)$ & $0.80(0.67-0.96)$ \\
\hline 2007 & & & $2007^{\mathrm{e}}$ & & \\
\hline Quartile 1 & 1.00 & 1.00 & Quartile 1 & 1.00 & 1.00 \\
\hline Quartile 2 & $0.71(0.60-0.84)$ & $0.78(0.65-0.94)$ & Quartile 2 & $0.73(0.63-0.84)$ & $0.78(0.67-0.91)$ \\
\hline Quartile 3 & $0.71(0.60-0.84)$ & $0.80(0.67-0.97)$ & Quartile 3 & $0.67(0.58-0.77)$ & $0.78(0.67-0.92)$ \\
\hline Quartile 4 & $0.64(0.54-0.77)$ & $0.64(0.53-0.78)$ & Quartile 4 & $0.53(0.46-0.61)$ & $0.58(0.49-0.68)$ \\
\hline 2009 & & & $2009^{f}$ & & \\
\hline Quartile 1 & 1.00 & 1.00 & Quartile 1 & 1.00 & 1.00 \\
\hline Quartile 2 & $0.75(0.63-0.89)$ & $0.88(0.72-1.06)$ & Quartile 2 & $0.69(0.60-0.80)$ & $0.74(0.63-0.87)$ \\
\hline Quartile 3 & $0.69(0.58-0.81)$ & $0.85(0.70-1.02)$ & Quartile 3 & $0.65(0.56-0.74)$ & $0.70(0.59-0.82)$ \\
\hline Quartile 4 & $0.74(0.62-0.87)$ & $0.88(0.73-1.07)$ & Quartile 4 & $0.59(0.51-0.67)$ & $0.66(0.56-0.77)$ \\
\hline
\end{tabular}

\footnotetext{
All analyses are weighted

${ }^{a}$ Adjusted for gender, age, household income, education, physical activity level, smoking status and chronic disease

${ }^{\mathrm{b}}$ Included Newfoundland and Quebec $(\mathrm{n}=24,136)$

${ }^{\mathrm{c}}$ Included New Brunswick, Ontario and Yukon/Northwest Territories $(\mathrm{n}=12,184)$

${ }^{\mathrm{d}}$ Included Prince Edward Island, Alberta and British Columbia $(\mathrm{n}=26,656)$

${ }^{\mathrm{e}}$ Included Nova Scotia and Quebec $(\mathrm{n}=26,384)$

${ }^{\mathrm{f}}$ Included Quebec, Alberta and Saskatchewan $(\mathrm{n}=37,732)$
} 
Table 3. Odds ratios (OR) with 95\% confidence intervals for the association between fruit and vegetable intake and depression (Canada, 2000-2009).

\begin{tabular}{|c|c|c|c|c|}
\hline \multirow[t]{2}{*}{$\begin{array}{l}\text { CCHS } \\
\text { Survey Cycle }\end{array}$} & Fruit & ntake & \multicolumn{2}{|c|}{ Vegetable Intake } \\
\hline & $\begin{array}{l}\text { Crude OR } \\
(95 \% \text { CI })\end{array}$ & $\begin{array}{l}\text { Adjusted OR } \\
(95 \% \mathrm{CI})^{\mathrm{a}}\end{array}$ & $\begin{array}{l}\text { Crude OR } \\
(95 \% \text { CI }) \\
\end{array}$ & $\begin{array}{l}\text { Adjusted OR } \\
(95 \% \mathrm{CI})^{\mathrm{a}}\end{array}$ \\
\hline $\begin{array}{l}2000-01 \\
\text { Quartile 1 } \\
\text { Quartile 2 } \\
\text { Quartile 3 } \\
\text { Quartile 4 }\end{array}$ & $\begin{array}{l}1.00 \\
0.68(0.63-0.73) \\
0.65(0.59-0.71) \\
0.84(0.76-0.93)\end{array}$ & $\begin{array}{l}1.00 \\
0.80(0.74-0.87) \\
0.75(0.68-0.83) \\
0.97(0.87-1.08)\end{array}$ & $\begin{array}{l}1.00 \\
0.82(0.76-0.88) \\
0.73(0.67-0.80) \\
0.86(0.79-0.94)\end{array}$ & $\begin{array}{l}1.00 \\
0.85(0.78-0.92) \\
0.82(0.74-0.90) \\
0.91(0.83-1.01)\end{array}$ \\
\hline $\begin{array}{l}2003 \\
\text { Quartile 1 } \\
\text { Quartile 2 } \\
\text { Quartile 3 } \\
\text { Quartile 4 }\end{array}$ & $\begin{array}{l}1.00 \\
0.62(0.53-0.71) \\
0.66(0.55-0.79) \\
0.67(0.55-0.82)\end{array}$ & $\begin{array}{l}1.00 \\
0.73(0.62-0.85) \\
0.84(0.69-1.03) \\
0.82(0.65-1.03)\end{array}$ & $\begin{array}{l}1.00 \\
0.76(0.64-0.90) \\
0.71(0.60-0.84) \\
0.75(0.63-0.89)\end{array}$ & $\begin{array}{l}1.00 \\
0.82(0.68-0.99) \\
0.82(0.68-1.00) \\
0.83(0.69-1.01)\end{array}$ \\
\hline $\begin{array}{l}2005 \\
\text { Quartile 1 } \\
\text { Quartile 2 } \\
\text { Quartile 3 } \\
\text { Quartile 4 }\end{array}$ & $\begin{array}{l}1.00 \\
0.73(0.61-0.87) \\
0.71(0.57-0.89) \\
0.68(0.52-0.88)\end{array}$ & $\begin{array}{l}1.00 \\
0.90(0.74-1.10) \\
0.88(0.69-1.14) \\
0.82(0.60-1.12)\end{array}$ & $\begin{array}{l}1.00 \\
0.77(0.62-0.96) \\
0.83(0.67-1.02) \\
0.93(0.76-1.15)\end{array}$ & $\begin{array}{l}1.00 \\
0.82(0.63-1.04) \\
0.92(0.73-1.16) \\
0.97(0.76-1.23)\end{array}$ \\
\hline $\begin{array}{l}2007 \\
\text { Quartile 1 } \\
\text { Quartile 2 } \\
\text { Quartile 3 } \\
\text { Quartile 4 }\end{array}$ & $\begin{array}{l}1.00 \\
0.60(0.51-0.70) \\
0.75(0.63-0.90) \\
0.67(0.56-0.80) \\
\end{array}$ & $\begin{array}{l}1.00 \\
0.70(0.59-0.83) \\
0.87(0.72-1.06) \\
0.71(0.58-0.88)\end{array}$ & $\begin{array}{l}1.00 \\
0.78(0.67-0.93) \\
0.70(0.59-0.83) \\
0.69(0.58-0.82)\end{array}$ & $\begin{array}{l}1.00 \\
0.84(0.70-0.99) \\
0.71(0.59-0.86) \\
0.65(0.54-0.79)\end{array}$ \\
\hline $\begin{array}{l}2009 \\
\text { Quartile 1 } \\
\text { Quartile 2 } \\
\text { Quartile 3 } \\
\text { Quartile 4 }\end{array}$ & $\begin{array}{l}1.00 \\
0.64(0.55-0.74) \\
0.62(0.52-0.74) \\
0.69(0.58-0.83)\end{array}$ & $\begin{array}{l}1.00 \\
0.77(0.65-0.92) \\
0.77(0.63-0.93) \\
0.82(0.67-1.01)\end{array}$ & $\begin{array}{l}1.00 \\
0.90(0.76-1.07) \\
0.80(0.67-0.96) \\
0.85(0.72-1.00)\end{array}$ & $\begin{array}{l}1.00 \\
1.03(0.85-1.24) \\
0.98(0.81-1.20) \\
1.00(0.83-1.20)\end{array}$ \\
\hline
\end{tabular}

All analyses are weighted

${ }^{\text {a }}$ Adjusted for gender, age, household income, education, physical activity level, smoking status and chronic disease 


\section{Fruit and Vegetable Consumption and Mental Health Disorders}

Table 4. Odds ratios (OR) with $95 \%$ confidence intervals for the association between total fruit and vegetable intake and secondary outcomes (Canada, 2003-2009).

\begin{tabular}{|c|c|c|c|c|c|c|}
\hline \multirow[t]{2}{*}{$\begin{array}{l}\text { CCHS } \\
\text { Survey Cycle }\end{array}$} & \multicolumn{2}{|c|}{$\begin{array}{c}\text { Presence of a Mood } \\
\text { Disorder }\end{array}$} & \multicolumn{2}{|c|}{$\begin{array}{c}\text { Presence of an Anxiety } \\
\text { Disorder }\end{array}$} & \multicolumn{2}{|c|}{ Perceived Mental Health } \\
\hline & $\begin{array}{l}\text { Crude OR } \\
(95 \% \mathrm{CI})\end{array}$ & $\begin{array}{l}\text { Adjusted OR } \\
(95 \% \mathrm{CI})^{\mathrm{a}}\end{array}$ & $\begin{array}{l}\text { Crude OR } \\
(95 \% \mathrm{CI})\end{array}$ & $\begin{array}{l}\text { Adjusted OR } \\
(95 \% \mathrm{CI})^{\mathrm{a}}\end{array}$ & $\begin{array}{l}\text { Crude OR } \\
(95 \% \text { CI })\end{array}$ & $\begin{array}{l}\text { Adjusted OR } \\
(95 \% \mathrm{CI})^{\mathrm{a}}\end{array}$ \\
\hline $2003^{b}$ & & & & & & \\
\hline Quartile 1 & 1.00 & 1.00 & 1.00 & 1.00 & 1.00 & 1.00 \\
\hline Quartile 2 & $0.81(0.73-0.90)$ & $0.87(0.78-0.98)$ & $0.77(0.68-0.86)$ & $0.85(0.75-0.97)$ & $0.73(0.65-0.81)$ & $0.83(0.73-0.93)$ \\
\hline Quartile 3 & $0.76(0.68-0.85)$ & $0.82(0.73-0.93)$ & $0.81(0.72-0.92)$ & $0.88(0.76-1.01)$ & $0.67(0.60-0.75)$ & $0.83(0.72-0.95)$ \\
\hline Quartile 4 & $0.82(0.74-0.92)$ & $0.91(0.80-1.03)$ & $0.82(0.73-0.92)$ & $0.94(0.81-1.09)$ & $0.58(0.51-0.65)$ & $0.77(0.67-0.90)$ \\
\hline $2005^{c}$ & & & & & & \\
\hline Quartile 1 & 1.00 & 1.00 & 1.00 & 1.00 & 1.00 & 1.00 \\
\hline Quartile 2 & $0.87(0.77-0.99)$ & $0.93(0.81-1.07)$ & $0.72(0.62-0.84)$ & $0.77(0.65-0.90)$ & $0.69(0.60-0.79)$ & $0.77(0.65-0.90)$ \\
\hline Quartile 3 & $0.78(0.69-0.89)$ & $0.85(0.74-0.98)$ & $0.71(0.62-0.83)$ & $0.80(0.68-0.95)$ & $0.56(0.49-0.64)$ & $0.67(0.57-0.79)$ \\
\hline Quartile 4 & $0.77(0.68-0.87)$ & $0.81(0.70-0.94)$ & $0.70(0.61-0.81)$ & $0.78(0.66-0.93)$ & $0.56(0.49-0.65)$ & $0.73(0.61-0.87)$ \\
\hline $2007^{d}$ & & & & & & \\
\hline Quartile 1 & 1.00 & 1.00 & 1.00 & 1.00 & 1.00 & 1.00 \\
\hline Quartile 2 & $0.73(0.66-0.80)$ & $0.81(0.73-0.90)$ & $0.74(0.66-0.82)$ & $0.81(0.72-0.92)$ & $0.62(0.55-0.70)$ & $0.71(0.62-0.81)$ \\
\hline Quartile 3 & $0.66(0.60-0.73)$ & $0.73(0.65-0.81)$ & $0.68(0.61-0.76)$ & $0.75(0.66-0.85)$ & $0.53(0.47-0.59)$ & $0.66(0.57-0.76)$ \\
\hline Quartile 4 & $0.62(0.56-0.68)$ & $0.68(0.61-0.77)$ & $0.64(0.58-0.71)$ & $0.71(0.63-0.80)$ & $0.44(0.38-0.50)$ & $0.55(0.47-0.64)$ \\
\hline $2009^{\mathrm{e}}$ & & & & & & \\
\hline Quartile 1 & 1.00 & 1.00 & 1.00 & 1.00 & 1.00 & 1.00 \\
\hline Quartile 2 & $0.71(0.64-0.78)$ & $0.82(0.73-0.92)$ & $0.67(0.60-0.76)$ & $0.75(0.65-0.85)$ & $0.66(0.59-0.75)$ & $0.76(0.66-0.87)$ \\
\hline Quartile 3 & $0.69(0.62-0.76)$ & $0.83(0.73-0.93)$ & $0.69(0.61-0.77)$ & $0.81(0.70-0.93)$ & $0.55(0.49-0.62)$ & $0.71(0.61-0.81)$ \\
\hline Quartile 4 & $0.64(0.57-0.71)$ & $0.74(0.65-0.84)$ & $0.62(0.55-0.70)$ & $0.68(0.59-0.79)$ & $0.42(0.37-0.48)$ & $0.57(0.49-0.66)$ \\
\hline
\end{tabular}

All analyses are weighted

${ }^{a}$ Adjusted for gender, age, household income, education, physical activity level, smoking status and chronic disease

${ }^{\mathrm{b}}$ Included all provinces $(\mathrm{n}=126,077)$

${ }^{\mathrm{c}}$ Included Prince Edward Island, Ontario, Alberta and British Columbia $(\mathrm{n}=67,273)$

${ }^{\mathrm{d}}$ Included all provinces $(\mathrm{n}=122,723)$

${ }^{\mathrm{e}}$ Included all provinces $(\mathrm{n}=117,051)$ 
Figure 1. Pooled estimate of the association between total fruit and vegetable intake and

\begin{tabular}{|c|c|c|}
\hline Study - & $\begin{array}{l}\text { Odds ratio } \\
(95 \% \mathrm{Cl})\end{array}$ & $\%$ Weight \\
\hline 2001 & $0.75(0.72,0.78)$ & 52.0 \\
\hline 2003 & $0.71(0.66,0.77)$ & 14.2 \\
\hline 2005 & $0.78(0.70,0.88)$ & 6.9 \\
\hline 2007 & $0.68(0.63,0.74)$ & 13.0 \\
\hline 2009 & $0.71(0.65,0.77)$ & 14.0 \\
\hline Overall $(95 \% \mathrm{Cl})$ & $0.73(0.71,0.75)$ & \\
\hline
\end{tabular}

depression from all five waves of the CCHS. 


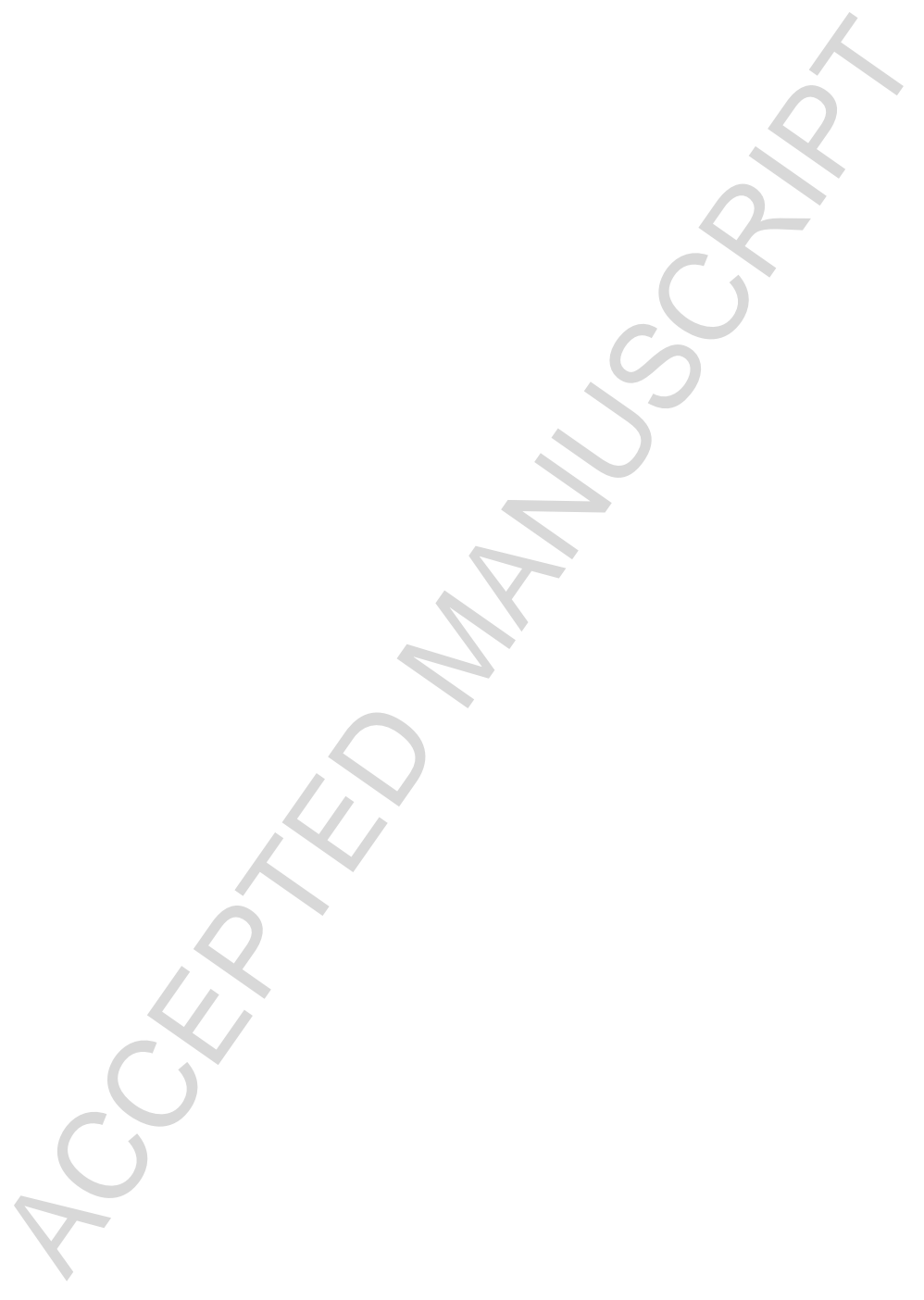




\section{HIGHLIGHTS}

- We studied five waves of a national survey ( $\mathrm{n}=258,357$ aged 12 years or older)

- Increased fruit and vegetable intake was associated with reduced odds of depression

- Fruit and vegetable intake was inversely associated with other mental health measures

- Results were consistent across five waves 


\section{University Library}

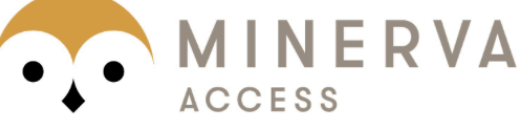

A gateway to Melbourne's research publications

Minerva Access is the Institutional Repository of The University of Melbourne

Author/s:

McMartin, SE;Jacka, FN;Colman, I

Title:

The association between fruit and vegetable consumption and mental health disorders: Evidence from five waves of a national survey of Canadians

Date:

2013-03-01

Citation:

McMartin, S. E., Jacka, F. N. \& Colman, I. (2013). The association between fruit and vegetable consumption and mental health disorders: Evidence from five waves of a national survey of Canadians. PREVENTIVE MEDICINE, 56 (3-4), pp.225-230. https:// doi.org/10.1016/j.ypmed.2012.12.016.

Publication Status:

Accepted manuscript

Persistent Link:

http://hdl.handle.net/11343/41832 